\title{
From Trepidation to Transformation: Strategies Used by Occupational Therapy Students on Role- Emerging Placements
}

\author{
Channine Clarke ${ }^{\star}$ \\ University of Brighton, United Kingdom \\ Richard de Visser \\ University of Sussex, United Kingdom \\ Gaynor Sadlo \\ Independent researcher, United Kingdom
}

\begin{abstract}
To prepare graduates for the diverse practice contexts in which they may work in the future, roleemerging placements are increasingly being used within curricula. Literature highlights the benefits and challenges of such placements but there has been little research to examine how students manage and overcome these challenges. Interpretative phenomenological analysis (IPA) was used to gain a deeper understanding of how five MSc pre-registration occupational therapy students coped with the challenges of undertaking a role-emerging placement. Interviews were carried out and analysed using IPA guidelines. The students utilised personal attributes, reflection, supervision, communities of practice, peer support and experiential learning to help them cope with, and overcome, the placement challenges. This enabled them to take ownership of their own learning and development, leading to positive placement outcomes. We conclude that students need to be encouraged to use and develop a range of strategies to overcome challenges of role-emerging placements. The findings build on existing accounts of students' experiences of role-emerging placements by providing deeper insights into the strategies they use to help them manage such placements successfully. Recommendations for further research are highlighted. Suggestions for placement preparation to facilitate students' coping strategies are made.
\end{abstract}

Keywords: coping strategies; placements; role-emerging;

"Corresponding Author: Channine Clarke, School of Health Sciences, University of Brighton, 49 Darley

Road, Eastbourne, East Sussex, BN20 7UR, United Kingdom Email: $\quad$ c.clarke@brighton.ac.uk

Journal URL: https://publications.coventry.ac.uk/index.php/pblh

Clarke, C., de Visser, R., and Sadlo, G. (2019) 'From trepidation to transformation: Strategies used by occupational therapy students on role-emerging placements'. International Journal of Practice-based Learning in Health and Social Care, 7 (1), 18-31 DOI: https://doi.org/10.18552/ijpblhsc.v7i1.508

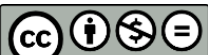

Cy NC ND (C) 2019 Channine Clarke, Richard de Visser, and Gaynor Sadlo. This Open Access article is distributed under the terms of the Creative Commons Attribution Attribution-Non-Commercial No Derivatives 4.0 International License (https://creativecommons.org/licenses/by-nc-nd/4.0/ ), which permits unrestricted non-commercial use, distribution, and reproduction in any medium, provided the original work is properly cited and is unaltered. 


\section{Introduction}

The College of Occupational Therapists (2014) highlights the importance of diverse placements in preparing students for the increasingly diverse range of practice contexts in which new graduates will work. One example is role-emerging placements "which occur at a site where there is not an established occupational therapist role" (College of Occupational Therapists 2006: 1). Students in these placements are supervised by an on-site employee and supported by an off-site occupational therapist. Examples include homeless shelters, refugee camps, residential homes and fire services.

Literature on role-emerging placements reveals that they have been part of the practice education of occupational therapy students in countries such as Canada and the United States for some time (Bossers et al. 1997, Overton, Clarke, and Thomas 2009). Although the benefits of such placements are becoming well established (Clarke, de Visser et al. 2014, Dancza et al. 2013, Mattila and Dolhi 2016), limited research has explored the way in which students manage challenges that they encounter when undertaking these placements (Clarke et al. 2015, Overton, Clarke, and Thomas 2009). This article presents one of the main themes that arose as part of a larger PhD study exploring occupational therapy students' experiences of roleemerging placements and the way in which these influenced their professional identity (Clarke 2012). Other themes have been reported elsewhere (Clarke, Martin, et al. 2014, Clarke et al. 2015).

\section{Literature review}

Internationally, role-emerging placements are increasingly being utilised in occupational therapy curricula with evidence indicating that student experience benefits such as increased clientcentred practice, empowerment, confidence in multidisciplinary team working, resource and time management, autonomous working, communication skills and strengthened professional identity (Clarke, Martin, et al. 2014, Clarke, de Visser et al. 2014, Dancza et al. 2013, Edwards and Thew 2011, Mattila and Dolhi 2016, Overton, Clarke, and Thomas 2009).

However, literature also highlights significant challenges for students undertaking such placements, such as initial anxiety, a lack of communication between on and off-site supervisors, staff attitudes towards occupational therapy, difficulties accessing support from part time supervisors, different expectations of students and staff, placement pace and managing emotions (Thew, Hargreaves, and Cronin-Davis 2008, Dancza et al. 2013, Clarke et al. 2015, Mattila and Dolhi 2016). Additional concerns raised by students include limited time with supervisor, short length of placement and lack of client contact (James and Prigg 2004, Prigg and Mackenzie 2002). Bossers et al. (1997) also identified that although students viewed role expansion positively in preparing them for diverse practice once qualified, some uncertainty was expressed about whether the roles undertaken were occupational therapy. Students have also expressed uncertainty about whether they should be screened for characteristics such as independence and confidence, with some feeling that this would help them cope more effectively on placement but others feeling that such skills could be developed on placement (Friedland, Polatajko, and Gage 2001).

Useful recommendations have been made to help address some of these issues, including placement tutors ensuring appropriate placement opportunities, identification of appropriate supervisors, provision of clear roles, responsibilities and expectations for all involved, preplacement preparation and induction days (Clarke et al. 2015, Edwards and Thew 2011, Overton, Clarke, and Thomas 2009, Thomas and Rodger 2011). However, these recommendations mainly focus on provision of support to students but there is limited consideration of the ways in which students themselves take ownership of managing challenges. This article presents the findings of one of the themes identified in the larger $\mathrm{PhD}$ study (Clarke 2012), providing a detailed understanding of the way in which students coped with 
challenges on their role-emerging placement and moved from feelings of anxiety and trepidation to ones of personal and professional transformation.

\section{Method}

\section{Research design}

Given that the aim was to explore students' experiences, Interpretative phenomenological analysis (IPA) (Smith, Flowers, and Larkin 2009) was deemed the most appropriate approach. IPA is designed to facilitate an in-depth exploration of an individual's experiences of a phenomenon and to understand the meaning that they attach to this. While individual cases can be explored, commonalities and divergences of experiences can also be considered across cases to facilitate a shared understanding (Smith, Flowers, and Larkin 2009). IPA was therefore felt to be the most useful approach in enabling the researcher to gain a richer understanding of how students experienced and coped with the challenges they encountered during their placements. It is also an approach that is increasingly being used within occupational therapy as one that is congruent with the profession's person-centred philosophy (Clarke 2009, CroninDavis, Butler, and Mayers 2009).

Yardley's (2008) principles for evaluating qualitative research were used to ensure rigour throughout the study. For example, the initial review of literature highlighted a gap in knowledge about students' experiences of role-emerging placements and thus provided a clear rationale for the study. Sensitivity and commitment were shown through listening closely and reflexively to participants' accounts and ensuring that data analysis was grounded in their data. Clear justification for all decisions made, in addition to an audit trail, ensured the study's transparency, and impact was demonstrated through the contribution of findings to the profession's knowledge base.

\section{Participants}

Following ethical approval from the University of Brighton, Faculty of Health Research Ethics and Governance Committee, all $39 \mathrm{MSc}$ (pre-registration) occupational therapy students about to undertake their final placement were emailed the research information sheet by the first author. This outlined the inclusion criteria that students would need to be when attending a roleemerging placement. As the researcher was a placement tutor at the time, it was important to minimise the risks of coercion. This was resolved by the researcher working solely on the University's BSc Occupational Therapy part-time course and having no contact with the MSc (pre-registration) course, with no involvement in placement allocation or academic assessment of this cohort.

Five female students who were undertaking a role-emerging placement consented to take part. At the time of the study this was an elective placement and the number of students choosing to do a role-emerging placement was small. Five was the total number of students undertaking a role-emerging placement at this time. IPA studies advocate small sample sizes in order to explore data at an individual level and provide readers with rich, detailed insights into the phenomena rather than making generalisations from a larger population (Smith, Flowers, and Larkin 2009).

Specific demographic detail was not collected regarding age or previous study but all participants were mature students who had completed a first degree and this was their final elective placement of the two-year course. Each student went individually on their placement which was full-time for eight weeks and occurred in a substance misuse rehabilitation centre, young person's mental health charity, forensic community team, homeless service or a refugee service. The students were supervised on a daily basis by an on-site educator (e.g. manager of the service, community psychiatric nurse) and an off-site occupational therapist with whom they met once a week for a minimum of an hour. Prior to the placement, all students had received 
half a day pre-placement preparation (e.g. regarding learning outcomes, role in supervision, assessment criteria) but this was not unique to those doing role-emerging placements.

\section{Data collection and analysis}

Semi-structured interviews are the method of choice for IPA studies (Smith, Flowers, and Larkin 2009), allowing participants to guide the interview and discuss what is important to them and their personal experiences. Interviews lasting 60-90 minutes were conducted after the completion of each student's placement. These were recorded, transcribed and analysed individually using IPA guidelines (Smith, Flowers, and Larkin 2009). The interviews and analysis was carried out by the lead author. The stages of analysis described by Smith, Flowers, and Larkin (2009) allowed consideration of context, language, content, the researcher's own interpretations and the subsequent building of emergent themes. Each transcript was analysed individually, congruent with the idiographic focus of IPA, and then over-arching themes were identified that reflected the shared experiences of the students. Reflexivity played an important role in ensuring that the researcher remained aware of the way in which their own values, beliefs, biases, assumptions, reading and role as placement tutor influenced the data analysis. At all stages of the research, diaries were maintained and discussed with supervisors and kept alongside data analysis as part of an audit trail to show how themes were interpreted and created.

\section{Findings}

Students identified a number of cognitive, emotional and ontological (i.e. sense of self) challenges in the early stages of their role-emerging placements. Although these findings are reported elsewhere (Clarke et al. 2015), it is useful to provide the reader with a brief summary. Students spoke of feeling temporarily overwhelmed by their experiences and that this affected their sense of self. Going into an unknown placement was compared to being "thrown into uncharted waters", and they felt alone and unprepared. They recognised how reliant they had previously been on the routines, structures and educators in traditional placements and the absence of this comfort zone increased their initial anxiety. Students identified challenges relating to different expectations that they had of themselves, based on their university placement learning outcomes and what they wanted to achieve, and those of their on-site educator who often had pre-conceived ideas about what the students would be able to offer them. They also felt an increased responsibility to get things right and to represent themselves, their university and the profession in the best way possible. These challenges were felt to be more profound than those on traditional placements due to the absence of an on-site occupational therapy educator who may previously have been able to guide them more quickly or deal with any conflict for them. However, it was being on their own and having to manage these challenges for themselves that led them to take ownership for their learning and which led to significant developments in their professional identity (Clarke et al. 2015).

Table 1: Themes and sub-themes

\begin{tabular}{|l|l|}
\hline Theme & Sub-theme \\
\hline Drawing on inner resources & $\begin{array}{l}\text { - Investing self in placement } \\
\end{array}$ \\
\hline Being part of the team & $\begin{array}{l}\text { - Making sense of the experience } \\
\text { - }\end{array}$ \\
& - Being empowered to develop \\
\hline
\end{tabular}


To help them manage these challenges, the students utilised various strategies which were ultimately important in helping them move forward and which contributed to a positive placement outcome. These strategies are presented here and form two themes (Table 1). All names used to report findings are pseudonyms.

\section{Drawing on inner resources}

The first theme addressed the personal characteristics that students identified as important in helping them to manage their emotions and successfully complete their placements. It also considers the way in which reflective practice acted as a transformative process, helping students make sense of their experiences.

\section{Investing self in placement}

All students suggested that only a 'certain type of student' (Sally) (one that had a genuine interest in the placement and was motivated to take on the challenges it presented) could be successful in a role-emerging placement. They had all chosen placements that had interested them, a factor they felt was important in keeping them motivated, particularly during difficult times. This intrinsic motivation was important for all students, and questions were raised as to whether a successful outcome would have been the same in a setting that had not interested them:

I had a real interest in the field as well so I was very excited about getting the chance to go to the [placement], I thought 'Wow the [placement]!'. So I guess a student would need that level of interest or at least be willing to develop that interest, because if I was put into an acute medical ward for my last placement I wouldn't have had the same passion (Sally).

The students' commitment to their placements continued even during the most challenging times and a clear sense of resilience and determination was evident throughout their accounts. For example, Jayne appeared to view her feelings of fear and anxiety about being on her own, having no occupational therapist on site, and not knowing what her role would be, as barriers that needed to be overcome. She did not to want to let herself down or spoil her past track record by ending with a negative placement and consciously drew on an inner determination to turn around negative feelings. Here, the way in which she switched between first and second person suggests she tried to distance herself from negative emotions and she can be heard giving herself encouragement in an attempt to prevent these feelings getting the better of her:

I was just adamant that l'd had really good placement experiences throughout the two years on this course. They have all been brilliant. I've learnt a lot from all of them, and I've loved them all and I didn't want to end the course on a bad experience, I just would have been gutted about it. So from that I just got a little bit of confidence to 'right just do it and get stuck in' and 'don't worry about it, you're fine' type attitude whereas before perhaps I was just a bit 'I don't like it, can't do it' and a bit negative and so yeah I kind of just got a, I don't know, like a strength from somewhere I suppose just to go out and face it and do it.

A similar intrinsic determination and sense of agency was displayed by other students who drew on self-belief and inner strength. Sophie's description of how she 'poured' herself into the placement illustrated the resolve and personal investment of all the students:

I knew right from the beginning that I wouldn't have gone and done a half-hearted job, that's just me and I worked really hard, did extra stuff away from placement and I did you know invest quite a lot, there was a lot of myself as well I really poured into it. 


\section{Making sense of the experience}

Reflective practice appeared to facilitate a transformative process that enabled the students to recognise their own development, increase their confidence and feelings of self-efficacy, change their ways of thinking and assist in the construction of their professional identity. Findings indicated that the absence of an on-site occupational therapist required students to be more active in the reflective process, leading to deeper levels of reflection than those experienced on traditional placements. Here, for example, Sally's depth of critical thinking and clinical reasoning led to the construction of her own knowledge and identity, a process she felt had been limited in its use on traditional placements:

You have to sit down and look at the core skills, 'How am I going to use them?' And then consistently throughout, you know, your reflective thinking: 'How have I used them? How was this intervention OT? What core skills did I use? What core skills have been developed? What skills could I have used that I didn't use? Why didn't I use those?' So there's way more challenging going on around that than there was had I been in a traditional setting where my educator asks me the questions and I answer, and there's no kind of greater scope than that.

Jayne and Sophie also highlighted the importance of reflective writing. Jayne, for example, used a diary as a private space and form of release (as her feelings 'poured' out of her) to help her make sense of her feelings. This helped her recognise her achievements and re-establish her self-confidence which had become lost due to high anxiety levels:

Three times a week I was writing in it and like each entry, you'd start off with 'what can I write about?' and you'd start with a sentence and then you'd just go on and on and on and it just all pours out of you into the diary and that was really useful to sort of reflect back on actually well I have done quite a lot there.

Reflection was particularly important when faced with the emotional demands of the work. In the absence of on-site occupational therapists, the students felt they had taken more personal responsibility for finding ways to deal with their emotions. For example, Poppy organised a team de-briefing session following an incident to help her normalise her feelings. This was something she felt she 'wouldn't have done if I had another OT there'.

\section{Being part of the team}

The second theme reflected the way in which being made to feel welcome and working as part of the team helped students adapt to their placement. They highlighted the importance of supervision and support, and valued practical experiences that gave them the opportunity to see their skills and knowledge in action. This led to a sense of achievement at being able to do what an occupational therapist would do and increased personal and professional confidence and belief.

\section{Sense of belonging}

Students' first impressions of their team affected how they felt about their placements. They highlighted how welcome they had been made and the positive impact this had on their confidence. They spoke of how they had been accepted as a person in their own right (not 'just a student'), an acceptance that was clearly important in making them feel respected, valued and empowered. Sophie appreciated the way that her team 'were so accepting and positive about the contribution I was making'. Similarly, Ella stated:

I was just part of the team and I said that to them at the end 'I'm really grateful 'cause you didn't make me feel like a little student who didn't have a clue, you just let me crack on, I was part of the team, I had a valued contribution'. 
Congruence between the way the teams worked and their own values and professional philosophy enhanced students' sense of belonging. They all felt their work was respected and were continually motivated by the team's interest in their roles. This appeared to provide a common bond that helped them fit into the team more effectively:

They seemed to really get quite excited about occupational therapy and what it means, more what I think occupations mean and how it, a lot of them are doing that anyway and are doing occupational therapy in a sense anyway at a different level erm, the way they worked was so great and so real and they really did get alongside people and they were using a person-centred approach and that was great 'cause I could talk a lot about how occupational therapists use a clientcentred approach and how important that is (Sophie).

Their sense of belonging led to feelings of sadness and loss at the end of the placements. Here Sophie described how she had felt so accepted and immersed in the placement that she had forgotten that she was a student and that it had to end:

I felt really sad I was so much part of the team and there were times when I would forget that I was going.

\section{Being empowered to develop}

Supervision from both the on-site educator and the off-site occupational therapist was seen as most important for providing space to talk about students' feelings, providing reassurance, validating their ideas and increasing self-confidence. It was particularly helpful in the early stages of the placement when students were dealing with initial anxieties. Speaking about her on-site educator, Jayne said:

It was just so valuable that supervision that I had with him every week erm I came away think, I went into supervision thinking 'Oh he's going to think this is rubbish, I'm not really doing OT' or 'My ideas are rubbish' and I came out thinking 'Oh actually l'm doing all right' 'cause he reassured me.

Similarly, when speaking about professional supervision, Sophie stated:

My OT educator was very supportive of me with that as well and I think that was very helpful, I think had I not have had someone to bounce those ideas off, to bounce those kind of concerns off erm it would have been harder for me.

An element of reciprocity was identified as a result of supervision where Sally's occupational therapy educator had been reminded of what occupational therapy was and had become inspired to seek out a more occupation-focussed job:

My educator was saying 'It's a very generic role' the first time I met her, and then my last supervision she said 'Oh l've actually applied for another job and it's specifically OT because you've inspired me to get back to my OT roots', which is amazing.

The trust and autonomy awarded to students by their placement teams made a significant difference to their confidence and led to feelings of empowerment:

Having that freedom of 'You know what, we think you can do it, here's your caseload and we entrust these people to you and we have good full faith in what you can do' and I kept getting really good feedback, that empowered me to continue on and grow in confidence (Ella). 
Peer support was a coping strategy used by some students. Whilst Sophie and Ella were the only students in their settings, they both highlighted the reassurance gained from contact with other role-emerging students:

You know, peers on emails and stuff we'd be chatting, that's what I would do to get me through 'cause you need that otherwise you do feel very much as though you're in a void on your own and you worry that you're not doing enough or you know you've missed something (Ella).

Meeting up with another student helped Sophie to normalise her initial feelings of anxiety and reminded her that she was not alone. Her use of the phrase 'cling on for dear life' reveals not just the vulnerability that she felt in the placement but also the support she gained from psychologically 'holding onto' the other student:

I'm really glad that I spent time with the other erm role-emerging student, that was really helpful just to kind of cling on for dear life at times 'cause it did feel, it did feel very tough and I know she felt similarly (Sophie).

\section{Learning through doing}

Students all recalled stories of therapeutic interactions with clients. These encounters were particularly meaningful in providing opportunities for students to put their skills and knowledge into action. It was through this work that students connected to the placement, made sense of their role and identity and were inspired to carry out their role as an occupational therapist:

The clients that I met were so inspiring and just the resilience that they had and the hope that they had in the face of all of this stuff that was going on that really kind of touched me and I thought if I can, if I can help you in any way through my knowledge or my training then you know I would love to (Sally).

I actually had a fantastic home visit, it was positive in terms of I really realised what I could do with this young person, from an OT point of view, so that made me sort of realise the positives that I could do (Poppy).

Running an art group was a 'turning point' for Jayne in terms of her feelings about herself and the placement. Whilst the group had been therapeutic for the clients there was a sense that it also acted as a therapeutic medium for her, helping her recognise that she did have the skills needed to complete the placement and gaining a sense of achievement at being able to do what an occupational therapist would do:

That was sort of sort of perhaps the turning point where I sort of thought 'Well actually you know I set this up, I planned it and organised it and am providing this for them' so I felt really proud of that and sort of thought 'Well actually you know I can do these things'.

The interventions described by the students all had a clear occupational focus. This demonstrated that, despite their initial anxieties about the lack of on-site occupational therapy structures to help guide their practice, they had understood their professional philosophy and been able to implement the occupational therapy role. Sophie highlighted the psychological rewards that such a successful encounter offered:

He was able to present this bit of creative writing that he had done and that was so wonderful to see his, just to see his face, just to see him, and he was a client that was particularly depressed and l'd given [him] this task of creative writing 'cause I knew it was something that he had been very interested in in the past and seeing him enjoying that occupation again. 


\section{Discussion and implications}

The students all took their role-emerging placements seriously and invested a lot of themselves, physically, cognitively and emotionally. They demonstrated courage, commitment, perseverance, agency and resilience, all of which have been cited as important learning attributes (Barnett 2007). As reported elsewhere (Clarke, Martin, et al. 2014) they drew on these attributes to help them re-stabilise the sense of self and emotional equilibrium that had been disrupted at the start of their placements. Whilst these attributes were similar to those considered important in other studies of role-emerging placements (Bossers et al. 1997, Friedland, Polatajko, and Gage 2001), and those identified as necessary for therapists working in diverse practice (Creek and Cook 2017), the way in which these have been used by students to help them overcome placement challenges has not previously been considered in any depth. Although it has been suggested that students should be screened for attributes such as selfconfidence and independence (Sullivan and Finlayson 2000), it has also been observed by students that these develop as a result of the role-emerging placement (Friedland, Polatajko, and Gage 2001). The latter observation is supported by the findings of this study and suggests that while such attributes may help students manage any early anxieties more effectively, it would be unfair to penalise those without such qualities from being able to undertake a roleemerging placement that appears to offer a significant transformative learning experience (Clarke, Martin, et al. 2014, Mattila and Dolhi 2016). The key consideration for academics and placement educators is how to encourage such students to develop these attributes both in practice and on campus. Strategies used by the University of Brighton are highlighted briefly in the conclusion.

Critical reflection was important in helping students make sense of their experiences and in facilitating their personal and professional development. This finding supports existing literature which highlights the value of reflective practice in role-emerging placements (Dancza et al. 2013, Knightbridge 2014, Mattila and Dolhi 2016, Thomas and Rodger 2011). In the absence of an on-site occupational therapy educator, students had to ask searching questions of themselves and the profession which led them to identify and challenge previously held assumptions and beliefs, to understand the relevance of the knowledge and skills learnt, and to construct their own knowledge and identity as occupational therapists. This can be likened to Conroy's (2003: 21) notion of "ontological reflection-in-action" as the students came to question their own 'ways of being' and became "conscious of realities other than the one into which they have been socialised" (Jarvis 2010: 99) on traditional placements. Dall'Alba and Sandberg $\underline{(2010)}$ ) suggest that such reflection is significant in extending students' knowledge beyond what they can do to who they are becoming as therapists, bringing about changes in their unfolding developmental trajectory.

The importance for students of developing a sense of belonging and having both on- and offsite educator and team support can be linked to van Manen's (2007: 106) "lived relation to the other". Here, the support, trust and validation that students received from those around them helped reduce their feelings of anxiety, confusion and self-doubt and played a significant role in the development of their professional ways of being, increasing their confidence in self and the profession. Congruent with findings of Levett-Jones et al. (2009), the sense of belonging that students experienced appeared to be an essential pre-requisite to learning, helping to free them from their initial anxieties so they could focus on their learning and development. To foster an early sense of belonging, induction days leading up to a role-emerging placement, as suggested by Thew, Hargreaves, and Cronin-Davis (2008), may be a useful strategy. Although studies have been carried out in nursing, research that explores occupational therapy students' belonging on practice placement, both traditional and diverse, is warranted.

Consistent with the findings of this study, existing research suggests that students value the opportunities for peer support in increasing their confidence and reducing feelings of isolation (Boniface et al. 2012, Dancza et al. 2013, O'Connor, Cahill and McKay 2012, Thew, Hargreaves, and Cronin-Davis 2008). This has implications for placement provision in both traditional and role-emerging settings where there may be better placement outcomes if 
students are placed in pairs. However, studies are needed to evaluate different models of roleemerging placements, including the benefits and limitations of peer learning.

Due to the lack of a traditional occupational therapy professional hierarchy in the placement setting, students no longer felt that they 'came under' an educator as had been the case on traditional placements. Consequently, they felt more respected and valued as individuals and able to establish a professional identity in their own right. This was similar to the sense of empowerment experienced by students in other role-emerging studies (Bossers et al. 1997, Prigg and Mackenzie 2002) but in stark contrast to findings from traditional placements where students have felt disempowered by their "naturally lowly position" (Tompson and Ryan 1996: 69). This reveals the way in which the structure of placements and the interactions between student and educator either serve to facilitate or constrain opportunities for becoming. This is supported by Duncan, Jones, and Carr (2008: 15) who suggest that the "architecture of the educational setting" creates a learning environment which either supports or inhibits a student. Whilst initially causing anxiety for the majority of students, the placement 'architecture' was such that it afforded them significant opportunities for personal and professional development, increasing their confidence, independent thought, reflective practice and identity development. It is this affordance that Billett (2010) argues is a key ingredient for effective practice-based learning.

Using Lave and Wenger's (1991) theory of situated participation, it could be suggested that students came to negotiate and understand themselves as professionals through their participation in the placement communities. This was evident in the awareness of self as occupational therapist that unfolded as a result of planning and carrying out what were seen as more authentic occupational therapy interventions. Students appeared to move away from the peripheral participation described by Wenger (1998) to more central participation as they took responsibility for developing the occupational therapy role. In doing so they earned professional acceptance from members of the team and gained a sense of empowerment and competency as they made an authentic contribution to the organisation. This impacted not only on the student but also on the community itself as team members came to reflect on, and change, their own practices and ways of being as a result of the students' presence. The reciprocal nature of the supervisory relationship, for example, indicates that such placements offer reflective opportunities for both student and educator. This supports the notion that transformation can occur for both the learner and practice community (Wenger 1998). It could be suggested that this is a key difference to traditional placements where students, whilst often being considered part of the team, may remain on the periphery of the teams' activities, carrying out designated tasks that contribute to those activities rather than being a central player in service development. Educators in all placement settings need to reflect on ways of encouraging more central participation to foster students' sense of efficacy and identity.

In contrast to literature that suggests occupational therapy students need to work alongside other therapists to develop a sense of identity (Fisher and Savin-Baden 2002, Tompson and Ryan 1996), findings indicate that students do not have to rely on occupational therapy communities of practice to develop this sense of self as therapist. Indeed, they suggest that it may be students' interactions with those outside of the profession, and the opportunities that this presents to reflect on their professional ways of being, that helps to enrich their becoming as occupational therapists.

\section{Limitations}

This study was carried out at one university with five female students, on role-emerging placements in a limited range of placement settings, and may not be representative of other students' experiences. However, true to the principles of IPA (Smith, Flowers, and Larkin 2009), the aim was not to generalise to the broader population, but to provide insights into the experiences and meaning-making of a purposively selected homogenous group. Other contextual factors may have influenced the findings. As mature students, for example, previous 
life and work experience may have helped them develop or utilise coping strategies more effectively than younger students. The problem-based learning approach learnt by the students on campus may also have provided them with additional coping strategies. Similarly, the findings need to be considered in the context of the placement settings which may have been particularly supportive. To what extent the findings are a result of the role-emerging placement setting / structure, the nature of the placement activities or the less frequent occupational therapy supervision is open to question, although findings would suggest it is a combination of these factors. Further research is required to determine whether students on other types of diverse or project-focussed placements, but which are not role-emerging, are able to use or develop similar strategies.

Whilst the interviews provided rich detail, they were retrospective accounts and reliant on student memories. The students had all passed the placement and this may have coloured the way they interpreted their experience. Richer insights may have been gained if interviews had been carried out throughout the placement itself.

\section{Conclusion}

The findings presented here suggest that students on role-emerging placements draw on a range of internal and external strategies that enable them to take ownership of their own learning and development and shift from initial feelings of anxiety, self-doubt and confusion to feelings of empowerment and personal and professional transformation. Although literature highlights external support mechanisms provided by universities or placement sites, the findings of this study add to the knowledge base by providing deeper insights into the strategies deemed important by the students themselves. Further research is warranted that explores other ways in which students overcome challenges on role-emerging placements in order to ensure they are designed and managed effectively and that students are supported appropriately.

At the University of Brighton, students have been supported to develop some of the strategies identified in this study through pre-placement visits and induction days. These enable them to meet their educators and establish sources of support early on, and to integrate into the placement community over time. Peer action-learning sets on campus that encourage reflection on placement aims, expectations, their role, and possible interventions, have proven to be useful in addition to linking the placement to the previous academic module where students have to design and present a poster for an occupational therapy intervention in their placement setting. This has led students to gain an understanding of the placement before they attend fulltime, to develop an interest in that setting and to reflect more deeply on their role which they report increases their confidence in self and the profession before they start the placement.

\section{Acknowledgements}

The authors thank the students that took part in this study and who shared their insightful experiences. 


\section{References}

Barnett, R. (2007) A Will to Learn: Being a Student in an Age of Uncertainty. Maidenhead: Open University Press, McGraw Hill

Billett, S. (2010) 'The practices of learning through occupations'. in Learning Through Practice: Models, Traditions, Orientations and Approaches. ed. by Billett, S. London: Springer, 59-81

Boniface, G., Seymour, A., Polglase, T., Lawrie, C., and Clarke, M. (2012) 'Exploring the nature of peer and academic supervision on a role-emerging placement'. British Journal of Occupational Therapy, 75 (4), 196-201

https://doi.org/10.4276/030802212X13336366278211

Bossers, A., Cook, J., Polatajko, H., and Laine C. (1997) 'Understanding the role-emerging fieldwork placement'. Canadian Journal of Occupational Therapy, 64 (1), 70-81. https://doi.org/10.1177/000841749706400107

Clarke, C. (2009) 'An introduction to interpretative phenomenological analysis: A useful approach for occupational therapy research'. British Journal of Occupational Therapy, 72 (1), 37-39. https://doi.org/10.1177/030802260907200107

Clarke, C. (2012) Occupational therapy students' experiences of role-emerging placements and their influence on professional identify. PhD Thesis, University of Brighton, UK.

Clarke, C., Martin, M., Sadlo, G., and de Visser, R. (2014) 'The development of an authentic professional identity on role-emerging placements'. British Journal of Occupational Therapy, 77 (5), 222-229 https://doi.org/10.4276/030802214X13990455043368

Clarke, C., de Visser, R., Martin, M., and Sadlo, G. (2014) 'Role-emerging placements: A useful model for occupational therapy practice education? A review of the literature'. International Journal of Practice-Based Learning in Health and Social Care, 2 (2), 1426 https://doi.org/10.11120/pblh.2014.00020

Clarke, C., Martin, M., Sadlo, G, and de Visser, R.. (2015) "'Facing uncharted waters": Challenges experienced by occupational therapy students undertaking role-emerging placements'. International Journal of Practice-Based Learning in Health and Social Care, 3 (1), 30-45 https://doi.org/10.18552/ijpblhsc.v3i1.212

College of Occupational Therapists (2006) Developing the occupational therapy profession: Providing new work-based learning opportunities for students. London: COT

College of Occupational Therapists (2014) College of Occupational Therapists' learning and development standards for pre-registration education. London: COT

Conroy, S.A. (2003) 'A pathway for interpretative phenomenology'. International Journal of Qualitative Methods, 2 (3), 36-62 https://doi.org/10.1177/160940690300200304

Creek, J., and Cook, S. (2017) 'Learning from the margins: Enabling effective occupational therapy'. British Journal of Occupational Therapy, 80 (7), 423-431 https://doi.org/10.1177/0308022617701490

Cronin-Davis, J., Butler, A., and Mayers, C. (2009) 'Occupational therapy and interpretative phenomenological analysis: Comparable research companions?'. British Journal of Occupational Therapy, 72 (8), 332-338 https://doi.org/10.1177/030802260907200802 
Dall'Alba, G., and Sandberg, J. (2010) 'Learning through and about practice: a lifeworld perspective'. in Learning Through Practice: Models, Traditions, Orientations and Approaches. ed. by Billett, S. London: Springer, 104-119

Dancza, K., Warren, A., Copley, J., Rodger, S., Moran, M., McKay, E., and Taylor, A. (2013) 'Learning experiences on role-emerging placements: An exploration from the students' perspective'. Australian Occupational Therapy Journal, 60, 427-435 https://doi.org/10.1111/1440-1630.12079

Duncan, J., Jones, C., and Carr, M. (2008) 'Learning dispositions and the role of mutual engagement: Factors for consideration in educational settings'. Contemporary Issues in Early Childhood, 9 (2), 107-117 https://doi.org/10.2304/ciec.2008.9.2.107

Edwards, M., and Thew, M. (2011) 'Models of role emerging placements', in Role Emerging Occupational Therapy. ed. by. Thew, M., Edwards, M., Baptiste, S., and Molineux, M. Chichester: Wiley-Blackwell, 15-35

Fisher, A., and Savin-Baden, M. (2002) 'Modernising fieldwork, part 2: Realising the potential'. British Journal of Occupational Therapy, 65 (6), 275-282 https://doi.org/10.1177/030802260206500605

Friedland, J., Polatajko, H., and Gage, M. (2001) 'Expanding the boundaries of occupational therapy practice through student fieldwork experiences: Description of a provinciallyfunded community development project'. Canadian Journal of Occupational Therapy, 68 (5), 301-309 https://doi.org/10.1177/000841740106800506

James, C., and Prigg, A. (2004) 'A self-directed fieldwork program to provide alternative occupational health placements for undergraduate occupational therapy students'. Australian Occupational Therapy Journal, 51, 60-68 https://doi.org/10.1111/.14401630.2004.00422.x

Jarvis, P. (2010) Adult Education and Lifelong Learning: Theory and Practice. 4th edn. Oxon: Routledge

Knightbridge, L. (2014) 'Experiential learning on an alternative practice education placement: Student reflections on entry-level competency, personal growth and future practice'. British Journal of Occupational Therapy, 77 (9), 438-446 https://doi.org/10.4276/030802214X14098207540956

Lave, J., and Wenger, E. (1991) Situated Learning: Legitimate Peripheral Participation. Cambridge: Cambridge University Press

Levett-Jones, T., Lathlean, J., Higgins I., and McMillan, M. (2009) 'Staff-student relationships and their impact on nursing students' belongingness and learning'. Journal of Advanced Nursing, 65 (2), 316-324 https://doi.org/10.1111/j.1365-2648.2008.04865.x

Mattila, A.M., and Dolhi, C. (2016) 'Transformative experience of master of occupational therapy students in a non-traditional fieldwork setting'. Occupational Therapy in Mental Health, 32 (1), 16-31 https://doi.org/10.1080/0164212X.2015.1088424

O'Connor, A., Cahill, M., and McKay, E.A. (2012) 'Revisiting 1:1 and 2:1 clinical placement models: Student and clinical educator perspectives'. Australian Occupational Therapy Journal, 59 (4) https://doi.org/10.1111/i.1440-1630.2012.01025.x

Overton, A., Clarke, M., and Thomas, Y. (2009) 'A review of non-traditional occupational therapy practice placement education: A focus on role-emerging and project 
placements'. British Journal of Occupational Therapy, 72 (7), 294-301 https://doi.org/10.1177/030802260907200704

Prigg, A., and Mackenzie, L. (2002) 'Project placements for undergraduate occupational therapy students: design, implementation and evaluation'. Occupational Therapy International, 9 (3), 210-236. doi:10.1002/oti.166.

Smith, J.A., Flowers, P., and Larkin, M. (2009) Interpretative Phenomenological Analysis. London: SAGE Publications Ltd

Sullivan, T.M., and Finlayson, M. (2000) 'Role-emerging fieldwork: The University of Manitoba approach'. OT Now, 2 (3), 24

Thew, M., Hargreaves, A., and Cronin-Davis, J. (2008) 'An evaluation of a role-emerging practice placement model for a full cohort of occupational therapy students'. British Journal of Occupational Therapy, 71 (8), 348-353 doi:10.1177/030802260807100809.

Thomas, Y., and Rodger, S. (2011) 'Successful role emerging placements: It is all in the preparation'. in Role Emerging Occupational Therapy. ed. by Thew, M., Edwards, M., Baptiste, S., and Molineux, M. Chichester: Wiley-Blackwell, 39-53.

Tompson, M.M., and Ryan, A.G. (1996) 'The influence of fieldwork on the professional socialisation of occupational therapy students'. British Journal of Occupational Therapy, 59 (2), 65-70 doi:10.1177/030802269605900208.

van Manen, M. (2007) Researching Lived Experience: Human Science for an Action Sensitive Pedagogy. Canada: The Althouse Press

Wenger, E. (1998) Communities of Practice: Learning, Meaning, and Identity. Cambridge: Cambridge University Press

Yardley, L. (2008) 'Demonstrating validity in qualitative psychology'. in Qualitative Psychology. A Practical Guide to Research Methods, 2nd Edition. ed. by Smith, J.A. London: Sage, 235-251 